\title{
Employing digital diplomacy in foreign policy: Israel as a model
}

\author{
BASMA KHALEEL NAMUQ M. A
}

Assistant Professor College of Political Science, University of Baghdad research field: political science: international studies

Assistant Professor Dr. Mohamed Aziz Abdul-Hassan Al-BAYATI

College of Political Science, University of Baghdad research field: political science: international studies Al JADRIYA Complex, Baghdad, Iraq karbala2070@gmail.com

\begin{abstract}
Objectives: Public diplomacy is one of the most important elements of soft power that states use to promote their values and ideas. Interest in the research and academic circles, as well as in official policy circles, has increased in the field of public diplomacy
\end{abstract}

The term "digital diplomacy" does not have a specific definition, but its main goal is to be "a way out of foreign policy problems using the Internet by communicating with the public directly without barriers

Digital diplomacy" as a solution to foreign policy problems using the Internet, or it is one of the uses of the Internet and information technology to achieve and implement the foreign policy goals of any country There are a number of goals that the use of "digital diplomacy" can achieve Being a source of information Take advantage of the massive flow of information in policymaking that allows for the prediction of social and political movements imminent, Open intelligence sources

Methodology/Approach: The study adopts an analytical, inductive approach that relies on uncovering facts by starting from the details, then proceeds gradually to laws, general rules, and the college, where the parts of the conceptual framework of Israeli digital diplomacy will be examined.

As the Israeli Ministry of Foreign Affairs has a team of ten members producing Arabic content for two Facebook pages (stand with us in Arabic, Israel speaks Arabic, Israel in Arabic, Israel Channel with the Heart, Israel Group in Arabic, Israel News in Arabic), Israel lovers from the Maghreb, the Middle East and Israel Jordan. etc.

These sites are supervised by the Department of Digital Diplomacy in Arabic - the second largest division of the Ministry of Foreign Affairs - to promote Israeli life and culture

At the same time we explained the challenges that stand in the way of achieving comprehensive Arab-Israeli normalization, and the recent scene in the adoption of Israeli foreign policy in the future on the concept of digital diplomacy as a strategy to confront the challenges that hinder the achievement of comprehensive Arab-Israeli normalization

Results: Our research treatment of the issue of the impact of employing digital diplomacy on Israeli foreign policy as one of the main drivers of the implementation of Israeli foreign policy

An objective analysis was carried out accompanied by a scientific study and logical conclusions based on the method of analysis away from repetition and verbosity and came out with several conclusions, including the following :

Israel's digital diplomacy rests on a strategic base

Since it is not currently possible to achieve a settlement based on "ending the conflict and ending claims" with 
the Palestinians on its own terms, it must therefore struggle with the Palestinian veto that has long been in force in Israeli relations. With the rest of the world, especially the Arab countries. According to this doctrine, the more Israel succeeds in establishing health systems in cooperation with leading regional and international powers, the greater the pressure on Palestinian leaders to review their current policies.

Indeed, the strategy of bypassing the Palestinians provided significant gains for Israel. Close relations have been forged with countless countries that previously pursued negative or even hostile policies toward Israel

The end of 2020 resulted in the signing of Israeli normalization and strategic cooperation agreements in various fields with the Arab Gulf states, led by the UAE and Bahrain, while Sudan hastened in the footsteps of the Arab Gulf states to sign normalization. And cooperation agreements with Israel. Many Arab countries are expected to sign in 2021

Conclusions : The Israeli foreign policy has the advantage of being and still is active, and the reason lies in the integration of digital public diplomacy into the decision-making process in the Israeli foreign policy and its implementation

Israel succeeded in establishing health systems in cooperation with leading regional and international powers, with increasing pressure on Palestinian leaders to review their current policies.

Indeed, the strategy of bypassing the Palestinians provided significant gains for Israel. Close relations have been established with countless Arab countries that have previously pursued negative or even hostile policies toward Israel.

More importantly, formal cooperation is expanding with Asian powers such as India, Japan and Vietnam, while informal relations with Indonesia are growing. To some extent, Israel has accomplished its "undeclared axis toward Asia" in the economic and security fields

In Europe, a de facto alliance is emerging with Cyprus and Greece (formerly the biggest critic of Israel in the European Union). A broader cooperation regime applies to natural gas fields in the eastern Mediterranean with Italy and other partners, while friendly diplomatic relations have been established with most countries in Eastern and Central Europe.

And public digital diplomacy is activated by integrating technology linking networks such as "Twitter", "Facebook" and "YouTube" into the professional "tools" for diplomats to serve the goals of their foreign policies

It is important for foreign ministries to deepen their commitment to using this technology, which is the platforms for interactive dialogue. Deepening this commitment is through taking measures, including the establishment of a public digital diplomatic apparatus to develop a comprehensive strategy for it to ensure coordination and clarity between government and semi-government agencies involved in implementing public digital diplomacy. The link between digital public diplomacy goals, means of implementation, and content

Israel will reap the benefits of regional relations from the concessions it made to the Palestinians, and this idea has been on the table since the Saudis proposed the "Arab Peace Initiative" in 2002, which promised to establish full relations with all Arab states (and thus, Islamic countries) in exchange for the illusion of Israel's withdrawal. A continuation of the 1967 borders.

But the agreement with the UAE put the matter in its real size, transforming a hypothetical possibility into a tangible reality.

Given the strength of the Israeli and Emirati economies, boycotts by critics of the Jerusalem-Abu Dhabi partnership will be ineffective and are likely to harm the boycotts more than the targeted victims.

What matters is whether Israeli and Emirati assets - especially symbols of their partnership, such as embassies, joint ventures, airlines, and tourist sites - will become the target of terrorist attacks by Tehran, Ankara, and their local proxies such as Hezbollah and Hamas.

The prospects for Saudi-Israeli normalization will remain a reality in the coming months of 2021 
Establishing gradual normalization arrangements with several Arab states appears to be the most likely path for the near-term development of Israeli digital diplomacy to the Arab-Israeli peace process, rather than an impending series of historic agreements similar to the agreement signed by the UAE.

The United States of America can help accelerate the pace of gradual transformation through mediation, sponsorship, or participation in specific initiatives.

Key words : Employing digital diplomacy foreign policy Israel model

DOI: $10.7176 / \mathrm{IAGS} / 90-05$

Publication date: April 30th 2021

\section{1. : the concept of digital diplomacy and its importance in the industrial process}

The term "digital diplomacy" so far has no specific definition, but its main goal is to be "a way out of foreign policy problems using the Internet by communicating with the public directly without barriers".

.The British Foreign Office defines it as a "solution to foreign policy problems using the Internet," while "Vargas Hanson" of the Brookings Center defined it as "one of the use of the Internet and information technology to achieve diplomatic goals." There are a number of other goals that the use of "Digital Diplomacy(Olsson, E. K. (2013). Public diplomacy )

Being a source of information Take advantage of the massive flow of information in policymaking that can predict the social and political movements that are about to happen open intelligence sources

Public diplomacy is one of the most important elements of soft power that countries use to promote their values and ideas. Interest in the research and academic circles, as well as in official policy circles, has increased in the field of public diplomacy(Bjola, C., \& Holmes, M. (2015).

According to the Digital Strategy Report issued by the British Ministry of Foreign Affairs in 2017, "Through the Internet, we can expand the scope of direct communication with civil society as well as governments and influential individuals," reflecting the way the ministry uses the Internet as a multi-mechanism social tool(Khatib, L., Dutton, W., \& Thelwall, M. (2012). Public diplomacy 2.0 ).

As Thomas Friedman says in The New York Times, "Social networks have forced most politicians to engage in a two-way dialogue with foreign audiences (Metzgar, E. T. (2015). Is it the Medium or the Message Social Media American )

\section{Goals of digital diplomacy : 2 .}

There are a number of other goals that the use of "digital diplomacy" can achieve

Being a source of information Take advantage of the massive flow of information in policymaking that can predict the social and political movements that are about to happen open intelligence sources

Public diplomacy is one of the most important elements of soft power that countries use to promote their values and ideas. Interest in the research and academic circles, as well as in official policy circles, has increased in the field of public diplomacy(Pamment, J. (2012). New public diplomacy )

The first decade of the 21 st century witnessed the emergence of digital public diplomacy, which is intended to harness the Internet and modern communication technology to communicate with an external audience with the aim of creating an enabling environment for a country's foreign policy, thanks to digital platforms that represent a new nervous system for the world. It has become possible to communicate instantly with the "Internet 
communities" that are an increasingly important political force in the process of making foreign policy in their countries, which calls for the GCC countries to integrate digital public diplomacy in the process of foreign policy decision-making and implementation.

Countries with active foreign policies have realized the importance of integrating digital public diplomacy into the foreign policy decision-making process, as digital public diplomacy enables foreign policy by communicating it to an external audience, to explain its goals and objectives, present its contexts and backgrounds, and defend it (Cull, Nicholas J. 2009“Public Diplomacy ).

Hence, every country trying - through its digital public diplomacy - to promote its vision and weaken the vision of its competitors towards these issues, and foreign ministries that do not adapt to this change lose valuable opportunities to "define" the policies of their country, and thus to create an enabling environment for the goals of those policies. The choice for the modern diplomat is limited to whether or not he defines his country's policies for the "Internet societies" that have reached 2.5 billion people through social media(The rise and rise of international diplomacy by WhatsApp...

https://www.theguardian.com/technology/2016/nov/04/why-do-diplomats.

The number of US State Department accounts exceeded 300 accounts on "Twitter" and 400 pages on "Facebook" that write in English and the language of the host country, and the number of languages in which you tweet on "Twitter" reached 11 languages in 2013.

The number of American diplomats abroad who use digital public diplomacy tools reached nearly 900 , including 39 ambassadors. By May 2013, the number of followers of the Ministry of Foreign Affairs websites on Twitter and Facebook had reached 26 million, an increase of 350\% compared to January 2012 (Attias, S. (2012). Israel's new peer-to-peer diplomacy ).

This has prompted most countries in the world, especially developed countries, to activate digital diplomacy platforms, especially at the level of diplomatic practice. Today, digital diplomacy has become one of the most important diplomatic tools for any country, and this is what countries take very seriously(Hayden, C. (2015). Social media at state: Power, practice ).

Therefore, the "European Union" believes that the link between digital and cultural diplomacy is "the key to openness to peoples." Therefore, in recent years, he has developed digital platforms for preserving and disseminating European cultural heritage, and using this heritage in interaction with a global audience.

As for France, it came second, followed by the United States; Its cyber diplomacy has been termed "influence diplomacy. (CPD Perspectives on Public Diplomacy )

" In view of the achievement it has achieved in this regard, it has created the ability to listen to the public and exchange opinions with them directly through social media. The Ministry of Foreign Affairs has designated a monthly interactive session on the Twitter platform that allows French citizens abroad and citizens of other countries to communicate with officials and answer their questions, which achieves the greatest impact that serves the primary goal of digital diplomacy, that is, "addressing the public and influencing it directly without much cost (Zaharna, R. S., Arsenault, A., \& Fisher, A. (2014). Relational, networked and collaborative )

Creating public opinion and influencing its trends by attracting millions of viewers and followers from all over the world daily, via Facebook, in addition to accounts on Twitter, Instagram, a channel and YouTube (Manor, I. (2016). Are We There Yet: Have MFAs Realized the Potential of Digital Diplomacy?. )

\section{1.. Israeli digital diplomacy}

The great acceleration that the digital world is witnessing today with the increasing reliance on social media, which has become used by more than two billion people, which is an easy and low-cost media, makes it an effective tool in diplomatic work, directing policies and achieving goals (Fletcher, Tom, Naked Diplomacy. Power and Statecraft in the Digital Age, ed. Tom Fletcher. London: William Collins, 2016. 
The Israeli Ministry of Foreign Affairs has a team of ten members producing Arabic content for two Facebook pages (stand with us in Arabic, Israel speaks Arabic, Israel in Arabic, Israel channel with the heart, Israel group in Arabic, Israel news in Arabic, Israel lovers from the Maghreb and the Middle East, Israel in Jordan) Etc(.

These sites are supervised by the Department of Digital Diplomacy in Arabic - the second largest division of the Ministry of Foreign Affairs - to promote Israeli life and culture(Kampf, R., Manor, I., \& Segev, E. (2015). Digital Diplomacy 2.0 )

The Israeli Ministry of Foreign Affairs recently celebrated its ranking fourth in the world as the strongest digital connection with the world, expressing its hopes of achieving the forefront in this field, as one of the Israeli pages on Facebook managed to attract more than 1.6 million Arab followers, while the number of interaction with Israeli channels on The social network of nearly 220 million people from the Arab world.

The practical reality indicates that Israel moved from eighth place in the world in 2016 to fourth place in 2018, in the use of digital diplomacy, where it realized that hard tools have proven their failure to solve the conflict with the Arabs and that the hope is to exploit its soft power.

"Israel is communicating with new audiences in a way that goes beyond the borders that were impossible to cross in the past, thus opening personal channels of communication that allow us to achieve a future of cooperation and partnership," said Yuval Rotum, Director General of the Israeli Ministry of Foreign Affairs(Melissen, J., \& Caesar-Gordon, M. (2016). "Digital diplomacy ).

Given that the Middle East is home to about 280 million Arabs, of whom 145 million use the Internet, and 100 million use Facebook, as well as other communication networks, such as Twitter, Instagram, Snapchat and others, which are frequented by millions, most of them young people, Israel has realized that its strategy in The region should be directed towards Arab youth, which surveys have found that about $90 \%$ of them use these sites. Thus, exploiting this virtual reality is the only way to reduce and influence their minds.

In the context of this reality, one of the Israeli pages on Facebook - "Israel Speaks Arabic" - alone attracted more than 1.8 million Arab followers, focusing on topics such as Israeli cuisine, music and innovation, which contributed to its further spread and expansion.( Reem Khalil Abdul Rahman. Diplomacy and the art of negotiation )

"We receive messages every week from entrepreneurs and technology enthusiasts from various Arab countries who are interested in getting to know Israeli startups and opportunities to cooperate with them," said Yonatan Gonen, head of the department of Arabic-language communication sites at the Israeli Ministry of Foreign Affairs. Other social networks are approximately 220 million from the Arab world

. Israeli Channel Two revealed a confidential report by the Israeli Ministry of Strategic Affairs that classifies Jana Jihad Al-Tamimi (11 years), from the village of Nabi Saleh, as "a strategic threat to the State of Israel".

The report indicated that Jana, who is the cousin of the child Ahed Tamimi, who is detained in Israeli prisons, films the peaceful weekly rallies against settlement and the wall, which Israel has always rejected in her village, and publishes them on social media, using both Arabic and English, and has hundreds of thousands of followers around the world(Abdullah Hammoudat, Digital Diplomacy )

The video reports that A1-Tamimi publishes on social media and through which she addresses her audience in English, which she learned in the United States of America where she was born, has more than 20 thousand views per clip

The girl, Tamimi, makes an individual effort and publishes video clips that she filmed with her phone camera, not funded or supported by any party, but she was able to address the outside audience in his own language, embarrassing Israel and pushing some of its politicians to demand her arrest(Fletcher, Tom, Naked Diplomacy ) 


\section{3 . 2. The UAE-Israel agreement or the end of 2020 is a practical product of the success of Israeli digital diplomacy}

Because the announcement in August 2020 of a full normalization of relations between the UAE and Israel, which was arranged through the good offices of the United States.

It will open up opportunities for cooperation, partnership and synergy among the most dynamic and forwardlooking economies in the Middle East.

And that the agreement is "bigger" than many admit. It represents a major and shocking change in Arab-Israeli relations and came to put an end to 72 years of Arab states that do not share borders with Israel to reconcile with the Jewish state. From Morocco to Oman, these countries have maintained varying degrees of distancing, under the pretext of loyalty to the Palestinian cause (The Road Beyond UAE-Israel Normalization www.washingtoninstitute.org )

In fact, many of them were able to maintain their isolation, precisely because Israel provided many of the economic, agricultural, hydrological, security and intelligence benefits of the bilateral relations through secret channels, without the Arab side having to establish formal diplomatic relations with it in return.

Among the most prominent results of the Emirati-Israeli agreement, or the end of 2020

Realizing two strategic matters of utmost importance to Israeli digital diplomacy

First, the 18 Arab states will release the opposition under pressure to explain what specifically prevents them, as part of their commitment to the Palestinian cause, from enjoying the additional benefits provided by full normal relations with Israel that the UAE clearly believes will be accompanied by full normalization(Israel-United Arab Emirates normalization agreement..en.wikipedia.org ).

Second, there will be pressure on Israel to deny its friendly Arab countries the benefit of secret friendly meetings after the precedent set for legitimizing their relations

\section{The Israeli digital diplomacy rests on a strategic base}

Since it is not currently possible to achieve a settlement based on "ending the conflict and ending the claims" with the Palestinians according to its own terms, it must thus wrestle the Palestinian veto right that has been in place for a long time on Israeli relations with the rest of the world, especially the Arab countries. According to this doctrine, the more Israel succeeds in establishing health systems in cooperation with leading regional and international powers, the more pressure will be on Palestinian leaders to review their current policies(What's in Israel's Deal With Bahrain and the U.A.E.? WSJwww.wsj.com ).

Indeed, the strategy of bypassing the Palestinians provided significant gains for Israel. Close relations have been forged with countless countries that previously pursued negative or even hostile policies toward Israel(SudanIsrael relations agreed, Donald Trump announces..www.bbc.com )

One of the major ironies in the agreement with the Emirates is that Benjamin Netanyahu - the heir of the two hard-line leaders from the revisionist movement Ze'ev Jabotinsky and Menachem Begin, and the planner for the idea of the unilateral Israeli annexation of occupied territories in the June 1967 war - is the Israeli leader responsible for reintroducing the "link link." To the peace process equation

\section{Conclusion}

According to Israeli digital diplomacy, Israel has succeeded in establishing health systems in cooperation with leading regional and international powers, as the pressure increases on Palestinian leaders to review their current policies.

Indeed, the strategy of bypassing the Palestinians provided significant gains for Israel. Close relations have been 
forged with countless countries that previously pursued negative or even hostile policies toward Israel.

More importantly, formal cooperation is expanding with Asian powers such as India, Japan and Vietnam, while informal relations with Indonesia are growing. To some extent, Israel has accomplished its "undeclared axis toward Asia" in the economic and security fields.

In Europe, a de facto alliance is emerging with Cyprus and Greece (the former European Union's biggest critics of Israel). A broader cooperation regime applies to natural gas fields in the eastern Mediterranean with Italy and other partners, while friendly diplomatic relations have been established with most countries in eastern and central Europe.

The activation of digital public diplomacy is done by integrating the technology of linking to networks such as "Twitter", "Facebook" and "YouTube" in the professional "tools" for diplomats to serve the objectives of their foreign policies.

It is important for foreign ministries to deepen their commitment to using this technology, which represents interactive dialogue platforms. The deepening of this commitment is represented in taking measures, including the establishment of a digital public diplomacy apparatus that undertakes the development of a comprehensive strategy for it to ensure coordination between governmental and semi-government agencies concerned with implementing digital public diplomacy, and clarity of the link between the objectives, means of implementation and content of digital public diplomacy,

And that the Israeli foreign policy is distinguished by that it was and is still active, and the reason lies in the integration of digital public diplomacy into the process of Israeli foreign policy decision-making and implementation

Israel will reap the benefits of regional relations from the concessions it made to the Palestinians, and this idea has been on the table since the Saudis proposed the "Arab Peace Initiative" in 2002, which promised to establish full relations with all Arab countries (and thus, Islamic countries) in exchange for the illusion of Israel's withdrawal. Complete to the 1967 borders.

But the agreement with the UAE put the matter in its real size, turning a hypothetical possibility into a tangible reality.

Given the strength of the Israeli and Emirati economies, boycotts by critics of the Jerusalem-Abu Dhabi partnership would be ineffective and likely to harm the boycotters more than the targeted victims.

What matters is whether Israeli and Emirati assets - especially symbols of their partnership, such as embassies, joint ventures, airlines, and tourist sites - will become the target of terrorist attacks by Tehran, Ankara, and their local proxies such as Hezbollah and Hamas.

The possibilities of Saudi-Israeli normalization will remain a reality in the coming months of the year 2021

The Kingdom of Saudi Arabia, the main actor in normalization in the region, took a deliberate approach instead of pushing forward as President Trump urges, and hastening to take any step in this regard.

At the same time, the Saudis took steps to support the Emirati agreement even as they reaffirmed their commitment to the principles of the "Arab Peace Initiative." Soon, they agreed to use their airspace for flights between Abu Dhabi, Dubai and Tel Aviv, cutting travel time by hours. They also pressured the Palestinian Authority to stop publicly insulting the agreement, and to prevent the protesters from lighting Emirati flags

. More importantly, the secret contacts with Riyadh made Jerusalem completely confident that Saudi Crown Prince Mohammed bin Salman is intent on normalizing relations at some time in the future, despite the objections of some in the royal court and his father's reluctance to abandon the peace initiative. In Abu Dhabi, Crown Prince Mohammed bin Zayed justified his agreement with Israel by noting that he prohibits the annexation of some areas in the West Bank to the Jewish state.

Establishing gradual normalization arrangements with several Arab countries appears to be the most likely path 
for the near-term development of Israeli digital diplomacy to the Arab-Israeli peace process, rather than an imminent series of historic agreements similar to the agreement signed by the UAE.

The United States of America can help accelerate this gradual pace of transformation through mediation, sponsorship, or participation in specific initiatives.

The most important step is to ensure the speedy success of the Emirati normalization agreement, as a model for other potential partners, and to encourage them to surround the Palestinians with an Arab-Israeli "peace belt" that ultimately persuades Ramallah to seek an agreement

\section{References}

Olsson, E. K. (2013). Public diplomacy as a crisis communication tool. Journal of International Communication, $19(2), 219-234$.

Metzgar, E. T. (2015). Is it the Medium or the Message Social Media American Public Diplomacy. Global Media Journal, 2012.

Pamment, J. (2012). New public diplomacy in the 21st century: A comparative study of policy and practice. Routledge.

Attias, S. (2012). Israel's new peer-to-peer diplomacy. The Hague Journal of Diplomacy, 7(4), 482.473

Cull, Nicholas J. 2009“Public Diplomacy: Lessons from the Past”.

CPD Perspectives on Public Diplomacy, vol. 2, no. 19, 2009.

Manor, I. (2016). Are We There Yet: Have MFAs Realized the Potential of Digital Diplomacy?. Brill Research Perspectives in Diplomacy and Foreign Policy, 1(2), 1-110

Zaharna, R. S., Arsenault, A., \& Fisher, A. (2014). Relational, networked and collaborative approaches to public diplomacy: The connective mindshift. Routledge.

Kampf, R., Manor, I., \& Segev, E. (2015). Digital Diplomacy 2.0? A Cross-national Comparison of Public Engagement in Facebook and Twitter. The Hague Journal of Diplomacy (4)10.362

Melissen, J., \& Caesar-Gordon, M. (2016). "Digital diplomacy" and the securing of nationals in a citizen-centric world. Global Affairs, 2(3), 321-330.

Hayden, C. (2015). Social media at state: Power, practice, and conceptual limits for US public diplomacy. Global Media Journal, 2012. Bortree, D. S., \& Seltzer, T. (2009). Dialogic strategies and outcomes: An analysis of environmental advocacy groups' Facebook profiles. Public Relations Review, 35(3), 317-319;

Rybalko, S., \& Seltzer, T. (2010). Dialogic communication in 140 characters or less: How Fortune 500companies engage stakeholders using Twitter. Public Relations Review, 36(4), 336-341

Taylor, M., \&Kent, M. L. (2014). Dialogic engagement: Clarifying foundationalconcepts. Journal of Public Relations Research, 26(5), 384-398.

Kampf, R., Manor, I., \& Segev, E. (2015). Digital Diplomacy 2.0?

A Cross-national Comparison of Public Engagement in Facebook and Twitter. The Hague Journal of Diplomacy, $10(4), 331-362$.

The Road Beyond UAE-Israel Normalization 
www.washingtoninstitute.org

Israel-United Arab Emirates normalization agreement..en.wikipedia.org

What's Behind the New Israel-UAE Peace Deal? | Council ..www.cfr.org

What's in Israel's Deal With Bahrain and the U.A.E.? - WSJwww.wsj.com > World > Middle East 15 2020.9.1

Sudan-Israel relations agreed, Donald Trump announces..www.bbc.com > world-africa-54554286

Reem Khalil Abdul Rahman. Diplomacy and the art of negotiation and their impact on political decision-making. Master's thesis. Faculty of Economics and Administrative Sciences - Al-Azhar University - Gaza. 2014. P. 18

Abdullah Hammoudat, Digital Diplomacy: Why should we be careful in using it? Publication date 21/03/2019

Al-Dalgamouni's Spears: Electronic Warfare ... When a Computer Becomes Dead. Al-Jazeera Website.

Publishing date 2019

Fletcher, Tom, Naked Diplomacy. Power and Statecraft in the Digital Age, ed. Tom Fletcher. London: William Collins, 2016

Williamson, W. F., \& Kelley, J. R. (2012). Kelleypd: Public Diplomacy 2.0 Classroom. Global Media JournalAmerican Edition, 11, 21.

Bjola, C., \& Holmes, M. (2015). Digital Diplomacy: Theory and Practice. Routledge

Khatib, L., Dutton, W., \& Thelwall, M. (2012). Public diplomacy 2.0: A case study of the USdigital outreach team. The Middle East Journal, 66(3), 453-472

The Road Beyond UAE-Israel Normalization

www.washingtoninstitute.org

Israel-United Arab Emirates normalization agreement..en.wikipedia.org

What's Behind the New Israel-UAE Peace Deal? | Council ..www.cfr.org

What's in Israel's Deal With Bahrain and the U.A.E.? - WSJwww.wsj.com > World > Middle East 15 2020.9.1

Sudan-Israel relations agreed, Donald Trump announces..www.bbc.com ～world-africa-54554286

Reem Khalil Abdul Rahman. Diplomacy and the art of negotiation and their impact on political decision-making. Master's thesis. Faculty of Economics and Administrative Sciences - Al-Azhar University - Gaza. 2014. P. 18

Abdullah Hammoudat, Digital Diplomacy: Why should we be careful in using it? Publication date 21/03/2019

Al-Dalgamouni's Spears: Electronic Warfare ... When a Computer Becomes Dead. Al-Jazeera Website.

Publishing date 2019

Fletcher, Tom, Naked Diplomacy. Power and Statecraft in the Digital Age, ed. Tom Fletcher. London: William Collins, 2016

The rise and rise of international diplomacy by WhatsApp

https://www.theguardian.com/technology/2016/nov/04/why-do-diplomats-use-this-alien-whatsapp-emoji-for$\underline{\text { vladimir-putin }}$ 